\title{
Condições de Vida dos Trabalhadores Brasileiros: balanço e perspectivas da pesquisa histórica Nauber Gavski da Silva ${ }^{I^{*}}$
}

\section{RESUMO}

SILVA, N. G. da. Condições de vida dos trabalhadores brasileiros: balanço e perspectivas da pesquisa histórica. A proposta deste artigo é retomar a temática das condições de vida dos trabalhadores, realizando um breve diagnóstico da produção corrente e apresentando perspectivas de pesquisa para a historiografia brasileira. Primeiramente, serão introduzidos conceitos básicos deste tipo de estudo, como padrão de vida, condições de vida e qualidade de vida. A seguir, serão apresentados balanços sobre a temática das condições de vida realizados nas décadas de $1980 \mathrm{e}$ 1990. Em consequência, reafirmarei o papel central de Thompson na reconfiguração da abordagem sobre as condições de vida dos trabalhadores. Finalmente, serão demonstrados alguns estudos recentes sobre o tema e serão sugeridas possibilidades de pesquisa, destacando a necessidade de retomar fontes tradicionais e explorar novas.

Palavras-chave: historiografia social; condições de vida; trabalhadores.

\section{ABSTRACT}

SILVA, N. G. da. Living conditions of workers in Brazil: situation and prospects of historical research. The aim of this article is resume the subject of workers ' living conditions, performing a brief diagnosis of the current production and presenting research perspectives for the Brazilian historiography. First, basic concepts of this type of study will be introduced, such as standard of living, living conditions and quality of life. Afterwards, balance statements will be presented on the subject of living conditions conducted in 1980 and 1990. Then we reaffirm the central role played by Thompson in reconfiguring the historic approach on the workers living conditions. Finally, it will be presented some recent studies on the topic and suggestions for state possibilities of research, highlighting the need to resume traditional and sources and to explore new ones.

Key words: social historiography; living conditions; workers.

\section{INTRODUÇÃO}

Inicialmente faz-se necessário definir alguns termos para que o leitor acompanhe com clareza o que será exposto a seguir. Quando utilizamos um vocábulo para tratar de um tema demasiado complexo não estamos realizando uma escolha arbitrária, nem estamos tratando os termos como sinônimos. Vejamos que o significam, respectivamente, condições de vida, padrão de vida e qualidade de vida.

Primeiramente, o termo "condições de vida" refere-se a um campo de estudos existente ao menos há dois séculos (desde o surgimento dos problemas sociais com o advento da Revolução Industrial), que passou a receber atenção das pesquisas acadêmicas especialmente a partir do século XX. Ainda hoje, em diversas disciplinas (como História, Sociologia, Antropologia, Economia, Estatística, 
entre outras), o tema das condições de vida das pessoas é abordado a partir de diversas perspectivas teóricas. Como veremos abaixo, de fato foram utilizadas diversas expressões para tratar desse tema (situação, questão social, padrão de vida etc.), mas, atualmente, se é difícil encontrarmos uma definição precisa sobre quais elementos compõem as condições de vida, ao menos existe um aparente consenso em torno do uso do termo, restrito à designação das formas pelas quais as pessoas vivem para além das suas atividades de trabalho. Portanto, em uma palavra, "condições de vida" é um amplo campo de estudos de diversas áreas das ciências.

Em segundo lugar, o termo "padrão de vida” não sofre da mesma indefinição. Também possuindo historicidade própria, é usado há muito tempo especialmente por grupos sociais ligados a governos e administradores de políticas econômicas e sociais que o utilizam com a intenção de observar e comparar a riqueza das sociedades/nações a partir de indicadores de renda dos habitantes. Para tal, produziram indicadores econômicos, como a divisão do Produto Interno Bruto (a soma de todas as riquezas produzidas em um país em dado período) pelo número de habitantes, como equivalente da renda de cada pessoa em dado país, o que supostamente permitiria comparar o estágio de desenvolvimento econômico de cada sociedade ou nação. A seguir, um refinamento do uso do termo levou a uma utilização mais próxima da realidade da vida das pessoas. Passou-se a calcular o efetivo poder de compra de mercadorias e serviços pelos salários de cada classe social e, desde então, este uso é mais próximo do atual conceito de padrão de vida. Em resumo, atualmente diz respeito ao poder de compra de mercadorias e serviços por determinado grupamento social, a partir dos seus rendimentos. É, portanto, um objeto de estudo, mas de alcance limitado para explicação da dinâmica social, pois se refere estritamente a uma das facetas do aspecto econômico da vida: o poder de compra de certo grupo social ${ }^{1}$. Como sinônimo, também é utilizado o termo "nível de vida".

Finalmente, o conceito de "qualidade de vida" foi desenvolvido apenas recentemente (a partir das décadas de 1970-1980), exatamente como proposta de superação dos limites da perspectiva do "padrão de vida" (OUTHWAITE, BOTTOMORE, 1996, p. 635-636; NUSSBAUM, SEN, REYES MAZZONI, 1996). Também utilizado para analisar o tipo de vida que as pessoas levam, difere-se do anterior na medida em que sua abordagem não se restringe à capacidade de compra de mercadorias e serviços por determinado grupo social. Na verdade, embora ainda hoje sem uma definição conclusiva, igualmente serve para medir o "desenvolvimento", agora não mais restrito ao aspecto econômico; utiliza-se o elemento complementar "humano" com a intenção de avaliar diversas facetas da vida. Assim, a qualidade de vida de determinado grupo ou indivíduo deve ser avaliada a partir de uma série de elementos considerados como fundamentais para que as pessoas sejam capazes de realizar atividades diversas em suas vidas. Tais elementos seriam (entre outros): graus de liberdade política; acesso e promoção efetiva da educação e saúde; adequação das condições ambientais para suas vidas; níveis de igualdade/desigualdade de gênero, raça e renda. Para efeitos de análise comparativa entre sociedades diversas, a Organização das Nações Unidas utiliza desde os anos 1990 um índice baseado nesta renovação conceitual, chamado de Índice de Desenvolvimento Humano, composto por: renda per capita, tempo de educação e expectativa de vida (como elementos que expressariam as condições econômicas, educacionais e de saúde das populações) (SEN, ANAND, 1994), embora tal seja criticado especialmente por utilizar apenas alguns indicadores sociais (GRANADOS, 1995; SAGAR, NAJAM, 1998) e desconsiderar o papel ativo dos agentes (FUKUDA-PARR, 2003). Em resumo, "qualidade de vida" é um conceito para análise do tipo de vida que as pessoas levam, mais rico que "padrão de vida", mas que ainda sofre certo grau de indeterminação. De qualquer forma, poucos historiadores (e outros profissionais) vêm realizando estudos históricos a partir dessa perspectiva teórica, como veremos mais adiante neste artigo. 
Realizada esta breve incursão na definição dos nossos termos básicos, podemos adentrar propriamente na primeira parte deste artigo, onde será possível visualizar como a historiografia vem se apropriando da temática e dos conceitos acima apresentados e quais as referências teóricas e metodológicas mais importantes para o estudo das condições de vida dos trabalhadores brasileiros. Na segunda parte do artigo, serão apresentadas as formas pelas quais estudos recentes vêm abordando o tema, bem como as possibilidades de pesquisa histórica e fontes que devem ser consideradas.

\section{BALANÇOS BIBLIOGRÁFICOS}

$\mathrm{Na}$ década de 1980, o antropólogo brasileiro José Sérgio Leite Lopes realizou um balanço sobre a produção intelectual - em diversos campos do conhecimento - relativa às condições de vida dos trabalhadores desde o século XIX (LOPES, 1984). Demonstrou como, em cerca duzentos anos, diversos vocábulos foram utilizados para tratar do tema das condições de vida das camadas populares e como as polêmicas em torno desse objeto foram adentrando paulatinamente os muros acadêmicos através de debates entre diversos profissionais (economistas, sociólogos, historiadores), especialmente a partir dos anos 1930. Em resumo, durante o século XX ocorreram mudanças fundamentais no significado da categoria "condições de vida": se até o início do século tais condições eram passíveis de avaliação objetiva pelos governos, cada vez mais tais ponderações foram sendo minadas com a renovação da abordagem proposta por alguns grupos acadêmicos, os quais passaram a considerar como igualmente relevante o ponto de vista das próprias pessoas cujas vidas eram avaliadas. Tal renovação é observável nos estudos de Maurice Halbwachs (abordando as representações da classe operária), Pierre Bourdieu (observando a importância da cultura e das experiências da classe operária) e Richard Hoggart (um "nativo" da classe operária tornado "antropólogo", que descreveu sua cultura a partir da vida familiar, do bairro, etc.). Em todo caso, segundo Leite Lopes, sem dúvida fora o historiador E. P. Thompson quem realizou de forma mais completa o movimento teórico de incorporação do ponto de vista da própria classe trabalhadora na análise das suas condições de vida, através da observação das suas experiências e cultura²

Na década seguinte (anos 1990), o historiador Norberto Osvaldo Ferreras, de forma mais resumida, refez o balanço da produção sobre o tema, dedicando atenção à apropriação realizada pelas historiografias brasileira e argentina das condições de vida dos trabalhadores, através dos estudos sobre Rio de Janeiro e Buenos Aires (FERRERAS, 1997). Ferreras constatou que ambas as produções geralmente estavam balizadas, até os anos 1970-80, em variáveis quantificáveis que as compunham ${ }^{3}$.Em resumo, tais estudos seguiam senão as conclusões teóricas, ao menos os princípios metodológicos da "ortodoxia acadêmica" europeia e estadunidense, que até os anos 1960 se baseava no argumento de que havia ocorrido uma melhora nos níveis/padrões de vida dos trabalhadores com o advento da Revolução Industrial, observáveis na comparação entre salários e preços das mercadorias. A renovação dessa abordagem ocorreria na América Latina a partir da introdução do marxismo britânico, nos anos 1980, através dos referenciais teóricos e metodológicos pertinentes ao tradicional debate acadêmico sobre padrão de vida dos trabalhadores ingleses. Novamente, E. P. Thompson aparece para Ferreras como referencial fundamental para o estudo da temática, tal qual apareceu em Leite Lopes. E é possível afirmar que ainda hoje (anos 2010), ele se mantém atual. Vejamos o porquê. 


\section{ATUALIDADE DE THOMPSON PARA A TEMÁTICA DAS CONDIÇÕES DE VIDA}

Nesse sentido, inicialmente demonstrarei a inserção histórica do autor nos debates sobre "padrão de vida” do período Pós-Segunda Guerra. Logo, apresentarei o resultado daquelas controvérsias, consolidado na criação do Î́ndice de Desenvolvimento Humano adotado pela Organização das Nações Unidas a partir de 1990. Não se trata de demonstrar que Thompson teria influenciado a criação do IDH - o que parece pouco provável - mas pensar nos motivos que fazem com que o autor permaneça atual para estudar as condições de vida dos trabalhadores. O que pode ser demonstrado é que as premissas teóricas de Thompson vêm se consolidando nos índices adotados pela ONU desde a década de 1990 para medir as variantes do que se chama contemporaneamente de "qualidade de vida".

Na clássica $A$ formação, de Thompson, penso ser possível identificar uma articulação teórica central no texto, a saber, a vinculação entre condições de vida e a experiência da exploração, marcadores do surgimento da classe operária inglesa ${ }^{4}$. Não é necessário aqui demonstrar todo o percurso do argumento do autor, mas apenas apresentar aspectos essenciais daquela articulação teórica ${ }^{5}$. Em resumo, arrisco afirmar que para aquele historiador, do século XVIII para o XIX, os trabalhadores ingleses teriam sido forçados, ao mesmo tempo, à sujeição política e social, que, se não era uma novidade em suas vidas, ao menos coincidia com uma revolução na França, com uma crescente autoconsciência e aspirações mais ambiciosas, com um surto populacional nas grandes cidades e com a transparência ou mesmo intensificação de formas de exploração econômica. Todos esses elementos contribuíram "para a coesão social e cultural do explorado" (THOMPSON, 1987, vol. 2, p. 22). Aqui, creio, fica explícito o sentido que o autor pretendia atribuir à sua proposta teórica apresentada no Prefácio. Como afirma Thompson, não foi qualquer experiência que "moldou" o nascimento da classe operária inglesa. Houve, sim, uma hierarquia entre as experiências possíveis ${ }^{6}$. Claro que há relutâncias na historiografia em atribuir esse percurso teórico ao autor?

Em resumo, foi a partir dos mecanismos que colocaram em marcha a Revolução Industrial que "aconteceu" a classe operária inglesa: aquelas pessoas experimentaram, fundamentalmente, uma alteração na natureza e intensidade da exploração, que se tornara mais transparente, ocorrendo, simultaneamente, uma maior opressão política, ambas em comparação com as relações sociais predominantes até o século XVIII. A forma como esses trabalhadores experimentaram e trataram essas mudanças, em termos culturais, é que lhes conferiu uma consciência de classe (THOMPSON, 1987, vol. 1, p. 10). É exatamente a leitura adequada de Thompson, no que diz respeito ao tratamento cultural das experiências pelas quais passaram os trabalhadores, que alimentou a publicação da coletânea brasileira de Batalha, Silva e Fortes (2004).

Essa "descoberta" de Thompson provém dos debates com sociólogos e economistas em torno do tema do "padrão de vida", nos quais ele estava inserido antes da publicação de $A$ formação, em 1963. Em resumo, seus estudos sobre o tema o levaram a conclusões sobre a experiência da exploração baseadas na deterioração das condições de vida dos trabalhadores na transição do século XVIII para o XIX. Contra os argumentos dos economistas, Thompson apresentou uma proposta de análise que historiadores espanhóis chamaram de variante da "qualidade de vida" (AIZPURU, RIVERA, 1994) ${ }^{8}$. Thompson demonstrou que trabalhar com a ideia de "padrão de vida" era complicado porque, se por um lado, salários e artigos de consumo são mensuráveis em estatísticas, por outro alguns aspectos da vida não são igualmente ponderáveis, tais como alimentação, moradia, saúde, vida familiar, ócio, educação, lazer, disciplina e intensidade no trabalho. Enquanto no "padrão de vida" seria possível medir quantidades, para compreendermos o "modo de vida" é necessária uma descrição, e geralmente avaliação de qualidades (THOMPSON, 1987, vol. 2, p. 36 - 
37). É exatamente pela avaliação da qualidade das condições de vida que o autor consegue chegar à conclusão anteriormente apresentada, de que a experiência crucial da Revolução Industrial fora a da exploração e da opressão política.

Ao lado das relações de trabalho - onde certamente havia exploração econômica, mas de percepção não imediata -, os âmbitos através dos quais as pessoas pobres percebiam uma exploração intensa de forma aparentemente imediata eram exatamente aqueles presentes na já referida controvérsia historiográfica do padrão de vida. Apesar do imperativo das relações de trabalho nas suas vidas dentro das fábricas, oficinas e minas (entre outros), onde a dominação de classe era evidente, nunca ocorreu a reunião de todos os trabalhadores ao mesmo tempo em um mesmo espaço fabril para então decidirem formar uma classe, a qual dariam o nome de "operária". Na verdade, "sua reunião em formações de classe que transcendam essas unidades individuais [de trabalho] é um processo diferente, que depende tanto de sua consciência de uma experiência e de interesses comuns quanto de sua disposição de agir sobre eles" (WOOD, 2003, p. 85). Só há classe onde há autoidentificação de classe9. O estudo histórico de Norberto Ferreras sobre o cotidiano dos trabalhadores em Buenos Aires, no período de formação da classe operária portenha (1880-1920), corrobora essa tese ${ }^{10}$.

Realizada essa incursão nos avanços da teoria histórica sobre a constituição da classe operária, veremos agora que os debates posteriores ao texto d'A formação de Thompson, no campo do pensamento econômico, especialmente sobre a questão do padrão de vida, parecem indicar que esta perspectiva específica (do foco nas "necessidades" das pessoas), seria a mais correta na avaliação das condições de vida dos trabalhadores e que a observação exclusiva do problema do acesso a mercadorias como fator definidor do tipo de vida que as pessoas levam seria insuficiente. Essa perspectiva seria consolidada nos debates dos economistas nas próximas décadas. Vejamos de que forma.

\section{A CONSOLIDAÇÃO DO CONCEITO DE “QUALIDADE DE VIDA”}

Durante a década de 1980, o economista indiano Amartya Sen trabalhou, entre outros temas, o significado do conceito de "padrão de vida". Suas reflexões sobre a pobreza e padrão de vida se inserem no contexto de debate nos países ricos após a Segunda Guerra Mundial sobre a "liberdade de querer/desejo" (freedom of want) dos seus cidadãos (SEN, 1983) ${ }^{11}$. Como ele assegura, o fim da pobreza virou o grande tema da política dos países ricos (SEN, 1987). Não é fortuita, portanto, a preocupação de Thompson, quando escreve $A$ formação (anos 1950-60), com as questões relativas à melhora/piora do padrão de vida da nascente classe operária inglesa ao final do século XVIII.

Em resumo, segundo a proposta de Sen, deveríamos superar a mera identificação da renda per capita de um país para nos aproximarmos de uma real compreensão quanto às condições de vida de sua população: não se trataria apenas de uma questão de opulência de mercadorias ${ }^{12}$. Portanto, o conceito de "padrão de vida" seria demasiado restrito para compreendermos a dinâmica social e precisava de um substituto.

Sen questiona se o acúmulo de mercadorias seria o lugar correto para pararmos na definição do padrão de vida. Tal acúmulo seria o padrão de vida em si? Por que devemos nos focar (fundamentalmente) na opulência, em vez de prestar atenção ao que as pessoas conseguem fazer ou ser?, questionamentos muito parecidos com a crítica de Thompson ao grupo dos autores "otimistas", na controvérsia sobre o padrão de vida da nascente classe operária inglesa. Como vimos anteriormente, um maior acesso a mercadorias úteis para a vida (seja para nos dar prazer, atender nossos desejos ou nos garantir 
possibilidade de escolha) não significa automaticamente um maior/melhor padrão de vida. Mesmo com uma possível melhoria material das condições de vida, a Revolução Industrial fora sentida/ percebida pelos trabalhadores como experiência catastrófica. O que nos interessa saber é que foram estes questionamentos de Sen que abasteceram uma renoção teórica na avaliação que fazemos sobre a vida das pessoas: a busca das respostas levou os economistas ao conceito de "qualidade de vida".

Concluindo essa reflexão, vamos agora observar brevemente como alguns trabalhos, especialmente historiográficos, tem abordado essas questões. Como se verá, a proposta teórica de Sen para a análise das condições de vida ainda gera dificuldades para os pesquisadores de diversas áreas (inclusive Sociologia e Economia), e com a História não haveria de ser diferente.

Como exemplos, podemos citar estudos de historiadores profissionais, mas também de economistas que a partir da perspectiva de Sen, procuram aplicar indicadores contemporâneos ao passado. Em função do limite de espaço para reflexão, vamos nos deter aqui em alguns estudos históricos relacionados ao Brasil.

\section{O TEMA DAS CONDIÇÕES DE VIDA NA HISTORIOGRAFIA BRASILEIRA RECENTEMENTE}

Se existem produções historiográficas recentes em torno da temática das condições de vida nos países de língua inglesa e espanhola, renovada pelas questões levantadas por Thompson nos anos 1960 e por Sen na década de 1980 (embora este não busque inserção no campo historiográfico), elas não perecem ter se consolidado da mesma forma no Brasil, apesar da presença do primeiro autor como referencial analítico nos últimos 30 anos $^{13}$. E é possível afirmar que Sen praticamente inexiste para nossa historiografia social. Como há 15 anos afirmava Ferreras sobre Rio de Janeiro e Buenos Aires, "a questão das condições de vida está em uma etapa inicial e são várias as questões que devem ser analisadas com maior profundidade" (1997, p. 23) ${ }^{14}$.

No mesmo sentido, uma observação recente sobre a produção nacional da temática, excluindose Rio de Janeiro e São Paulo, corrobora a perspectiva apresentada por Ferreras. A historiadora Sílvia Petersen identificou e compilou por estado da federação os títulos de diversos estudos em seu Levantamento da produção bibliográfica e de outros resultados de investigação sobre a história operária e trabalho urbano fora do eixo Rio-São Paulo (PETERSEN, 2009). Um dos aspectos que chama nossa atenção é exatamente o baixo número de abordagens, dentre as mais de 900 , que tratam da temática das condiçóes de vida (aparentemente) de forma central: existem apenas quatro registros, sendo dois sobre o Rio Grande do Sul (dentre 394), um acerca do Paraná e outro relativo a Pernambuco (menos de $0,5 \%$ do total).

Igualmente, se observarmos os trabalhos apresentados no último Simpósio Nacional da Associação Nacional de História em 2011, dentre as 49 comunicações que traziam no título o vocábulo "trabalhadores", havia apenas três versando sobre habitação e um sobre alimentação de forma central (cerca de 8\%) ${ }^{15}$. Em nenhum desses encontramos a preocupação dos autores com a inserção de seus objetos na temática das condições de vida e não havia nem no corpo do texto, nem na bibliografia, referência alguma ao clássico d'A formação de Thompson ou a Sen. Consequentemente, quaisquer debates sobre padrão/condições/qualidade de vida estão ausentes. Da mesma forma, o único estudo encontrado no Scielo referente às condições de vida de trabalhadores escravizados não dialoga com Thompson ou com a historiografia pertinente às condições de vida (CASTELUCCI JR., 2010). 
Não tenho condições de explicar os motivos dessa lacuna, mas apenas constatar uma dupla ocorrência no que se refere à temática das condições de vida dos trabalhadores na historiografia social brasileira: 1) os estudos são escassos; 2) quando os elementos referentes às condições de vida são pesquisados, não há diálogo com a produção teórica pertinente. Mas existem exceções tanto pelo uso de Thompson que alguns historiadores realizam em suas pesquisas, como pela tentativa de abordagem histórica que economistas vêm realizando a partir das premissas de Sen.

No âmbito da historiografia brasileira, merece destaque especialmente a pesquisa de Norberto Ferreras sobre o cotidiano dos trabalhadores em Buenos Aires, onde observamos uma abordagem da alimentação e habitação como fatores aglutinadores da classe operária portenha, pois elementos centrais na constituição de sua identidade classista. A "exploração" era componente central tanto da "experiência" do mercado de trabalho como das condiçóes de vida (conceitos explicitamente invocados desde Thompson). Em resumo, "as condições do cotidiano permitiram unificar o sentimento de exploração comum, estabelecendo um modo de vida particular" (FERRERAS, 2006, p. 15).

Já sobre o Rio de Janeiro, merece destaque especialmente o primeiro capítulo do estudo de Marcelo Badaró Mattos, sobre as experiências compartilhadas entre escravos e livres na formação da classe trabalhadora carioca. Também se valendo do conceito thompsoniano de "experiência da exploração", o autor aborda, além das questões relativas ao trabalho propriamente dito, os aspectos da moradia, saúde, renda e escravidão/liberdade (MATTOS, 2008, p. 37-82).

Por outro lado, os economistas brasileiros que vêm se preocupando em realizar abordagens históricas a partir de reflexões sobre qualidade de vida, geralmente alimentam suas análises na produção de Amartya Sen. Em uma coletânea sobre a temática do padrão de vida (living standards) em diversos contextos latino-americanos, os "padrões de vida" aparecem da seguinte forma (explicitamente alimentados pela revisão teórica de Sen): bem estar físico ("biológico") através de dados de estatura, que nos remetem à medida da rede de nutrição da pessoa; o Índice de Desenvolvimento Humano (IDH ou $H D I$ ) aplicado ao passado; índices de "qualidade de vida"; cálculos de salários reais; mortalidade infantil; acesso à saúde e educação (SALVATORE, COATSWORTH, CHALLÚ, 2010, p. 2). O capítulo que versa sobre o Brasil fora elaborado pelos economistas Monasterio, Nogueról e Shikida, e diz respeito à variação da altura das pessoas no país e à possível medição da desigualdade a partir daqueles dados entre 1939 e 1981. Os autores utilizam Amartya Sen para legitimar o estudo da altura e das políticas públicas como indicadores de bem-estar, na perspectiva do bem-estar físico acima apresentada. Em todo caso, neste artigo parece que não restringem seu estudo aos trabalhadores (COATSWORTH, CHALLÚ, 2010, p. 167-195). Por outro lado, oportunamente um daqueles economistas realizaria um ensaio de história antropométrica sobre a altura dos trabalhadores gaúchos entre 1889 e 1920, baseando-se em dados coletados nas carteiras de trabalho disponíveis no Núcleo de Documentação Histórica da UFPel (MONASTERIO, SIGNORINI, 2008). Ali, aplicando análise regressiva (o mesmo método da pesquisa sobre o Brasil acima citada), os autores analisaram onze mil estaturas masculinas, chegando às seguintes conclusões: a) a população apresentava alturas (média de $169 \mathrm{~cm}$ ) que não estavam distantes das mais altas do mundo no período; b) os imigrantes não eram responsáveis por esse resultado; c) as alturas estiveram estagnadas ao longo do período e decaíram nos últimos cinco anos. Ou seja, tal evidência iria contra a visão consolidada de uma elevação no bem-estar dos gaúchos no período como consequência das políticas sociais (em educação e saúde) adotadas pelo governo do Partido Republicano Rio-Grandense. Na verdade, "os dados sugerem que não houve melhoria nas condições biológicas de vida dos gaúchos” (p. 124). 
Resumidas muito brevemente a forma como historiadores brasileiros (e alguns economistas) vêm abordando a temática das condições de vida dos trabalhadores, passamos à última parte deste artigo, referente à possibilidade de pesquisa daqui pra frente, considerando o que foi exposto até o momento.

\section{POSSIBILIDADES DE PESQUISA DAS CONDIÇÕES DE VIDA DOS TRABALHADORES BRASILEIROS}

Agora, gostaria de apontar algumas possibilidades de pesquisa para a história das condições de vida dos trabalhadores brasileiros. Não vamos abordar aqui o subtema da habitação, pois como vimos acima, ele vem sendo privilegiado em tais estudos (FERRERAS, 1997, p. 22-23).

Sem dúvida, um recorte temporal a ser privilegiado deve ser o período a partir do Primeiro Governo Vargas. A reformulação do Estado brasileiro, que passaria a intervir mais intensamente no direcionamento da economia nacional desde os anos 1930, gerou como um dos efeitos o já sabido reconhecimento da "questão social". Claro que os historiadores e cientistas sociais já vêm utilizando há algum tempo as fontes produzidas por instituições estatais do período ${ }^{16}$. Em todo caso, o uso de fontes "oficiais" ainda parece superficial, especialmente na abordagem das condições de vida. Existem outras fontes que parecem nos oferecer novas possibilidades de pesquisa - claro que sob a condição de que elaboremos perguntas adequadas. Portanto, gostaria de apresentar algumas sugestões de subtemas das condições de vida dos trabalhadores no Brasil, indicando possíveis fontes a explorar.

A legislação elaborada para a criação e manutenção do salário mínimo (existente desde 1940) é um subtema que merece ao menos uma revisão de fôlego dos historiadores. Em geral, o papel do salário mínimo no país foi interpretado a partir das realidades de Rio de Janeiro e São Paulo, exclusivamente. Mas seria possível alargarmos nossa visão sobre o tema no país? Minha sugestão é que sim, embora as condições de pesquisa com fontes “oficiais" ainda não sejam ideais.

Ocorre que para a elaboração do primeiro patamar monetário do salário mínimo (cujo valor não seria unificado nacionalmente até 1984), foi realizado em 1938 pelo Ministério do Trabalho um censo que investigou a vida de aproximadamente 1,5 milhões de trabalhadores em todos estados da federação, no interior e capitais ( $10 \%$ da população economicamente ativa ou quase $30 \%$ dos assalariados do país) (SABÓIA, 1985, p. 22-23). A ficha utilizada pelos recenseadores é um documento rico para entendermos diversos aspectos da vida dos trabalhadores e suas famílias; obviamente, faz-se necessário um trabalho de reflexão metodológica focado nas mediações da informação entre o que o entrevistado afirmava e o que o técnico do governo interpretava e registrava. Mesmo assim, se superarmos essa barreira, poderíamos ascender diversos dados referentes às condições de vida de milhares de pessoas, nos seguintes termos: localidade de residência; nome familiar; local de trabalho; cargo ocupado; principais alimentos utilizados pela família (com preços e quantidades consumidas mensalmente); parcela da renda despendida com alimentação; modo de acesso aos alimentos (compras em feiras, vendas, dos patrões, e/ou cultivo de hortas e criações domésticas); quantidade de refeições diárias; renda de cada componente da família; composição da família nuclear; tipo de moradia (coletiva/individual, estrutura física); utensílios domésticos; forma de acesso à água e a saneamento; despesa com aluguel, vestuário, higiene (se andavam com ou sem calçados), remédios e médicos; além das doenças mais comuns entre adultos e crianças das famílias ${ }^{17}$. As possibilidades de cruzamento desses dados são inúmeras, sendo possível aplicar metodologias quantitativa e qualitativa ao material. 
Evidentemente, a empolgação dos historiadores sociais brasileiros poderia facilmente ser abalada pela dificuldade de acesso ou inexistência/descarte de tais documentos. Em todo caso, minha aposta é que as fichas do Censo de 1938 estão estocadas em depósitos esquecidos nas dependências do Ministério do Trabalho (na sede ou nas delegacias regionais) ${ }^{18}$. Desse modo, dependemos em certa medida do sucesso da busca dessas fontes, bem como do reconhecimento da legitimidade do nosso trabalho pelo poder público brasileiro.

De qualquer forma, mesmo que eventualmente não tenhamos acesso a tais fontes, ainda existe outro grupo de documentos semelhante, que são as Pesquisas de Padrão de Vida, realizadas (ao menos) em São Paulo, Rio de Janeiro e Porto Alegre a partir dos anos 1930. Como exemplo do que é possível produzir com essa documentação, recomendo a leitura, especialmente pela preocupação metodológica, de um livro sobre alimentação popular em São Paulo em meados do século XX (RODRIGUES, 2011). Quanto a Porto Alegre, ainda não são de nosso conhecimento estudos históricos que tenham utilizado tais fontes ${ }^{19}$. E é provável que existam pesquisas similares em outras cidades brasileiras.

Outro subtema, correlato ao salário mínimo, é o da questão alimentar. No mesmo ano em que aquele fora executado, começaram a surgir legislação e instituições oficiais para resolver o problema do elemento identificado como principal componente dos gastos das famílias trabalhadoras brasileiras. A alimentação correspondia a mais de $50 \%$ do consumo em todos os estados da federação, segundo o Censo de 1938. Portanto, diversas pesquisas foram realizadas para avaliar como os brasileiros se alimentavam, em contexto de introdução dos princípios científicos da nutrição no país (VASCONCELOS, BATISTA FILHO, 2011; VASCONCELOS, 2002). Caso os historiadores consigam acessar os documentos originais, poderiam se valer de pesquisas do tipo realizadas nas seguintes localidades ${ }^{20}$ : Manaus (AM), com mais de mil famílias em 1943; São Luiz (MA) com 333 em 1943; Recife (PE) com 500 em 1934 e 666 em 1938; Salgueiro (PE) com 200 em 1943; Maceió (AL) com 363 em 1943; Distrito Federal com 12.106 em 1938 (há outras pesquisas de 1933, 1934 e 1936); São Paulo (SP) com mais de 220.000 famílias em 1935; Curitiba (PR) com $1.385 \mathrm{em} 1943$. Além disso, é possível acompanhar outras pesquisas pontuais no próprio Boletim do Ministério do Trabalho, Indústria e Comércio (1934-1948), onde o subtema alimentar dos trabalhadores era recorrente ${ }^{21}$. Ou ainda, no periódico dos nutricionistas brasileiros, que cobre um período de 1944 a $1969^{22}$.

Finalmente, para acompanhar a questão da saúde, é recomendável recorrer a variados tipos de fontes. Em todo caso, aqui abordarei apenas aqueles produzidos por órgãos ligados aos governos. Nesse sentido, nos anos 1940, é frutífero perceber o panorama da medicina brasileira conferindo as discussões do campo no contexto do após-guerra ${ }^{23}$, bem como acompanhar o desenvolvimento da "medicina do trabalho", que passou a desempenhar papel fundamental com a criação das leis trabalhistas ${ }^{24}$. Além disso, os programas de educação popular em saúde ganhariam fôlego desde os anos 1940 e devem ser estudados localmente para chegarmos a um patamar mais nítido da realidade nacional ${ }^{25}$. Em geral, os programas de educação popular em saúde estavam ligados a centros de saúde públicos ou de empresas, cuja abordagem histórica também se faz necessária ${ }^{26}$.

\section{CONCLUSÃO}

Apesar de se constituir em uma temática "tradicional" nas ciências humanas, as condições de vida dos trabalhadores ainda não vêm sendo abordadas pela historiografia brasileira de forma satisfatória, salvo raros estudos, que nem sempre dialogam com a produção teórica (da história 
social e da economia) pertinente. Não ignorarmos a relevância da obra de Thompson e de Sen para avaliarmos o tipo de vida que as pessoas levam é a chave para não reduzirmos nosso esforço à descrição das condições de vida. Com o avanço dos estudos relativos às ações estatais sobre a vida dos trabalhadores desde os anos 1930, abre-se a possibilidade de nos reapropriarmos de fontes já utilizadas e inquirirmos algumas novas.

\section{NOTAS}

\section{${ }^{1 *}$ Doutorando UFRGS}

${ }^{1}$ Para uma abordagem das críticas realizadas ao conceito de padrão de vida como explicativo da dinâmica social, tanto pelo economista Amartya Sen como pelo historiador E. P. Thompson, vide nas referências bibliográficas: Silva, 2012.

${ }^{2}$ Vide especialmente os capítulos intitulados Exploração e Padrões e Experiências no volume segundo da sua obra: THOMPSON, E. P. A formação da classe operária inglesa. 3 vols. Rio de Janeiro: Paz e Terra, 1987. Publicada em língua inglesa pela primeira vez em 1963. Segundo Lopes, outros historiadores seguiriam no mesmo sentido proposto por Thompson: Eric Hobsbawm, Roland Trompé e Michelle Perrot.

${ }^{3}$ Como exemplo (talvez único) dessa produção historiográfica no Brasil, ver nas referências: Lobo, 1971.

${ }^{4}$ Não sou original na abordagem de Thompson pela perspectiva da "experiência da exploração" articulada com os aspectos das condições de vida: Marcelo Badaró Mattos, ao tratar da formação da classe trabalhadora carioca sob esse prisma, já demonstrou a importância da "exploração no trabalho e seus rebatimentos nas condições de vida (saúde, moradia, transporte, alimentação) daqueles que dependiam do salário para viver” (MATTOS, 2008. p. 55-56). Sobre o mesmo processo, em Buenos Aires, Norberto Ferreras trabalha com o argumento central de que a exploração aglutinava a classe fora do mercado de trabalho, nos âmbitos da alimentação e habitação (um mesmo "modo de vida") (FERRERAS, 2006, p. 15 e 87).

${ }^{5}$ Vide o percurso do argumento de Thompson em Silva (2010, p. 23-35).

6 "Podemos agora constatar parte da natureza verdadeiramente catastrófica da Revolução Industrial e algumas das razões pelas quais a classe operária se formou nestes anos. $\mathrm{O}$ povo foi submetido, simultaneamente, à intensificação de duas formas intoleráveis de relação: a exploração econômica e a opressão política. [...] Para a maioria dos trabalhadores, a experiência crucial da Revolução Industrial foi percebida como uma alteração na natureza e intensidade da exploração. [...] Certamente, havia flutuações de mercado, colheitas ruins e todo o resto, mas a experiência de exploração intensa era constante, enquanto as demais causas do sofrimento eram variáveis. Essas últimas não atingiam os trabalhadores diretamente, mas através da refração de um particular sistema de propriedade e poder que distribuía os ganhos e as perdas com grosseira parcialidade". (THOMPSON, 1987, vol. 2, p. 23 e 32).

${ }^{7}$ Desde que sua proposta de análise começou a ser utilizada no Brasil, especialmente a partir da década de 1980, o conceito de "experiência" sofreu questionamentos quanto à sua capacidade explicativa, sintetizados na crítica de Emília Viotti da Costa, e que não parecem descabidos. Afinal, segundo ela, haveria de existir alguma hierarquia entre as possíveis experiências de vida em dados períodos. Caso contrário, por qual razão estaríamos falando de "classe" e não de "grupo", "estamento", ou qualquer outro conceito? Apesar da validade das perguntas de Costa, elas se baseiam em uma leitura de Thompson que não identifica experiências centrais para definição da classe operária, tese diante da qual me afasto, como se pode observar pelo que expus até aqui. Cf: Costa (1990, p. 7).

${ }^{8}$ Em todo caso, isso não significa que Thompson tenha se furtado em debater os procedimentos metodológicos adequados para analisar o padrão de vida dos operários. Segundo Alexandre Fortes, no segundo volume de $A$ formação, "Thompson realiza o minucioso trabalho de desmonte das metodologias quantitativas tradicionais por meio das quais os historiadores econômicos buscaram, a partir da década de 1920, estabelecer modelos que supostamente provariam, contra as esmagadoras evidências contemporâneas, uma melhora global do padrão de vida dos trabalhadores durante a revolução industrial”. (FORTES, 2006, p. 200). 
9 Esta afirmação existe desde Marx até Thompson: "Na medida em que milhões de famílias camponesas vivem em condições econômicas que as separam umas das outras, e opõem o seu modo de vida, os seus interesses e sua cultura aos das outras classes da sociedade, estes milhões constituem uma classe". (MARX, 1988, p. 75); "A classe acontece quando alguns homens, como resultado de experiências comuns (herdades ou partilhadas) sentem e articulam a identidade de seus interesses entre si, e contra outros homens cujos interesses diferem (e geralmente se opõem) dos seus." (THOMPSON, 1987, vol. 1, p. 10).

10 “A exploração era um dos principais componentes da experiência do mercado de trabalho", mas “intensificava-se em duas situações impossíveis de evitar: alimentação e habitação". De forma mais clara, pode-se dizer que "se por um lado a experiência do mercado de trabalho era heterogênea, homogeneizavam-se num outro campo as condições de vida", favorecendo a identificação de uma situação semelhante entre aquelas pessoas, uma verdadeira identidade de classe. (FERRERAS, 2006, p. 219).

${ }^{11}$ Um resumo referente à preocupação de Sen com a temática da pobreza pode ser conferido em Kerstenetzky (2000).

${ }^{12}$ Evidentemente, Sen não é um raio em um céu azul. Sua proposta de nova conceitualização do padrão de vida fora alimentada por estudos dos teóricos das "necessidades básicas" e dos "indicadores sociais", que dedicaram atenção à economia relacionada a conquistas sociais. Para uma lista dos autores dessas correntes, entre os quais está o próprio Sen, vide nota 9. (SEN, 1987, p. 24).

${ }^{13} \mathrm{O}$ uso da proposta analítica de Thompson é tímido em dois estudos que trataram de condições de vida respectivamente no Rio de Janeiro e São Paulo, entre os anos 1980-90: Lobo (1992); Decca (1983).

${ }^{14} \mathrm{Na}$ historiografia argentina, o diagnóstico é semelhante. (SURIANO, 2009, p. 35-36). Por outro lado, na historiografia uruguaia o uso de Amartya Sen para analisar a "qualidade de vida" no país é explícito. Utilizando compilações de dados quantitativos referentes ao trabalho, saúde, educação, demografia e distribuição da renda per capita, historiadoras tentaram apresentar novas conclusões sobre "a evolução da qualidade de vida" naquele país, além das restrições impostas a essa proposta de pesquisa (como a ausência de fontes ou de dados sistematizados), bem como a pouca atenção dedicada pelos pesquisadores a fatores como gênero. (CAMOU, MAUBRIGADES, 2005).

${ }^{15}$ São eles: FOGAGNOLI, Marcela. O SAPS e a boa alimentação: O Serviço de Alimentação da Previdência Social e os trabalhadores (1940-1950); AMARAL, Deivison G. Regulamentação da ocupação urbana e as campanhas dos trabalhadores por habitação em Belo Horizonte (1912-1930); VIEIRA, Jussara L. A questão habitacional em ritmo de samba - uma análise do ponto de vista dos trabalhadores cariocas durante as reformas urbanas (1900-1930); CALVO, Célia R. Sobre cidades: experiências e memórias dos trabalhadores - apontamentos de uma pesquisa. (XXVI SIMPÓSIO NACIONAL DE HISTÓRIA. ANPUH: 50 ANOS, 2012).

${ }^{16}$ Um dos exemplos mais emblemáticos é talvez a recorrência da utilização do Boletim produzido pelo Ministério do Trabalho, Indústria e Comércio (1934-1948). Disponível na PUCRS e UFRGS.

${ }^{17}$ Um modelo desta ficha de recenseamento pode ser consultado em: BRASIL. Serviço de Estatística da Previdência e Trabalho. Alguns aspectos da politica do salário mínimo. Rio de Janeiro: Gráfica Vitória, 1946, 206p. Localização: Biblioteca Mario Simonsen/FGV. 331.2155 S491.

${ }^{18}$ Em conversa com um funcionário da DRT em Porto Alegre, em 2011, ele revelou não haver arquivistas, bibliotecários ou historiadores no órgão. Por outro lado, afirmou haver documentação muito antiga em algum lugar da delegacia. Em e-mail ao Ministério do Trabalho, fui informado que provavelmente tal documentação, caso exista, estaria nas Delegacias Regionais.

19 Os dados compilados dessas pesquisas podem ser consultados nas bibliotecas da UFRGS. Ver: BUENO, Luiz de Freitas. Padrão de vida do operário industrial de Porto Alegre. Porto Alegre: Imprensa universitária, 1958. (Estudos e trabalhos n 2); ___. Índice do custo de vida do operário industrial de Porto Alegre. Porto Alegre: Gráfica da universidade do Rio Grande do Sul, 1961. (Estudos e trabalhos n 3); GRIJÓ, José Carlos. Pesquisa do padrão de vida do operário industrial de Porto Alegre. Porto Alegre: Faculdade de Ciências Econômicas da Universidade do Rio Grande do Sul, 1960. (Estudos e Trabalhos n 15). 
SILVA, N. G. da.

${ }^{20}$ BARRETO, João de Barros; COSTA, Oswaldo Lopes da. Informações sobre alguns aspectos do problema alimentar no Brasil. Oficina Sanitaria Panamericana, vol. 25, n 5, maio 1946. p. 403-408. Disponível em <http://hist.library. paho.org/Spanish/BOL/v25n5p403.pdf>, consulta em 29 de outubro de 2009.

${ }^{21}$ Fonte disponível em diversas instituições, como nas bibliotecas da UFRGS e PUCRS. Além disso, recomendo a leitura de documentação sobre a criação do Serviço de Alimentação da Previdência Social, também do Ministério do Trabalho, disponível no CPDOC/FGV.

${ }_{22}^{2}$ Arquivos Brasileiros de Nutrição. Disponível nas bibliotecas do CCS/UFRJ, Manguinhos/FIOCRUZ, com alguns exemplares nas bibliotecas da UFRGS.

${ }^{23}$ Vide: Anais do Congresso Brasileiro dos Problemas Médico-Sociais de Após-Guerra. $2^{\circ}$ vol. Segundo Congresso Médico-Social Brasileiro (25 de junho a 02 de julho de 1945). Bahia, [s. ed.], 1946. Biblioteca de Manguinhos/FIOCRUZ.

${ }^{24}$ Vide: Revista Médica do Trabalho (1946-1951). Disponível na Biblioteca Nacional e Biblioteca do IESC/UFRJ. Não encontrei outros exemplares.

${ }^{25}$ Como exemplo, sugiro o acompanhamento das campanhas de educação sanitária desenvolvidas no Rio Grande do Sul entre 1947-1970, que podem ser consultadas em: Seção de Educação Sanitária [do Departamento Estadual de Saúde do Estado do Rio Grande do Sul]. 2 volumes (1947-1956; 1957-1970). Biblioteca da Escola de Saúde Pública/RS.

${ }^{26}$ Ainda sobre o Rio Grande do Sul, é possível constituir um "panorama” das instituições de saúde desde os anos 1940 consultando a seguinte documentação: Arquivos do Departamento Estadual de Saúde do R. G. S. (1940-1949). Disponível na Biblioteca da Escola de Saúde Pública/RS.

\section{REFERÊNCIAS}

AIZPURU, Mikel; RIVERA, Antonio. Los proprietarios del trabajo: las nuevas condiciones de vida. In: Manual de historia social del trabajo. Madrid: Siglo Veinteuno, 1994. p. 81-115.

BATALHA, Cláudio H. M.; SILVA, Fernando T.; FORTES, Alexandre. Culturas de classe: identidade e diversidade na formação do operariado. Campinas: Editora da UNICAMP, 2004.

CAMOU, María Magdalena; MAUBRIGADES, Silvana. La calidad de vida bajo la lupa: 100 años de evolución de los principales indicadores. In: TARGA, Luiz Roberto; HERRLEIN JR., Ronaldo (orgs.). Anais. Segundas Jornadas de História Regional Comparada. Porto Alegre: PUCRS, 2005. p. 1-19.

CASTELLUCCI JR., Wellington. Nas franjas da plantation: trabalho e condições de vida de escravos e libertos em pequenas propriedades de Itaparica: 1840-1888. Rio de Janeiro: Tempo, vol. 14, n. 28, p. 193-221, jun. 2010.

COSTA, Emília V. Estruturas versus experiência: novas tendências na história do movimento operário e das classes trabalhadoras na América Latina: o que se perde e o que se ganha. Rio de Janeiro: BIB/ANPOCS, n. 29, p. 3-16, $1^{\circ}$ sem. 1990.

DECCA, Maria Auxiliadora G. A vida fora das fábricas: cotidiano operário em São Paulo (19271934). Campinas: Departamento de História da UNICAMP, 1983. Dissertação de Mestrado.

FERRERAS, Norberto O. Historia e historiografía de las condiciones de la vida obrera em Buenos Aires y Rio de Janeiro: un analisis comparativo. Assis: Pós-História, vol. 5, p. 11-32, 1997. 
. O cotidiano dos trabalhadores de Buenos Aires (1880-1920). Niterói: EdUFF, 2006.

FORTES, Alexandre. "Miríades por toda a eternidade": a atualidade de E. P. Thompson. São Paulo: Tempo Social, vol. 18, n. 1, p. 197-215, jun. 2006.

FUKUDA-PARR, Sakiko. The human development paradigm: operationalizing Sen's ideas on capabilities. Feminist Economics, vol. 9, issue 2-3, p. 301-317, 2003.

TAPIA GRANADOS, José A. Algunas ideias críticas sobre el índice de desarollo humano. Boletim Oficina Sanitaria Panamericana, vol. 119, n. 1, p. 74-87, jul. 1995.

KERSTENETZKY, Celia Lessa. Desigualdade e pobreza: lições de Sen. Revista Brasileira de Ciências Sociais, vol. 15, n. 42, p. 113-122, fev. 2000.

LOBO, Eulália Maria L. (coord.). Rio de Janeiro operário: natureza do Estado, conjuntura econômica, condições de vida e consciência de classe. Rio de Janeiro: Access Editora, 1992.

LOBO, Eulália Maria L. et al. Evolução dos preços e do padrão de vida no Rio de Janeiro, 18201930 - resultados preliminares. Rio de Janeiro: Revista Brasileira de Economia, vol. 25, n. 4, p. 235-265, out./dez. 1971.

LOPES, José Sérgio Leite. Anotações em torno do tema "condições de vida" na literatura sobre a classe operária. In: SILVA, Luiz Antonio M. (org.). Condições de vida das camadas populares. Rio de Janeiro: Zahar, 1984. (Debates Urbanos: 6). p. 21-58.

MARX, Karl. O 18 brumário de Luís Bonaparte. In: Manuscritos econômico-filosóficos e outros textos escolhidos. $4^{\mathrm{a}}$ ed. São Paulo: Nova Cultural, 1988. p. 1-82.

MATTOS, Marcelo B. Escravizados e livres: experiências comuns na formação da classe trabalhadora carioca. Rio de Janeiro: Bom Texto, 2008.

MONASTERIO, Leonardo M.; SIGNORINI, Mateus. As condições de vida dos gaúchos entre 1889-1920: uma análise antropométrica. Brasília: Revista Economia, vol. 9, n. 4, p. 111-126, dez. 2008.

NUSSBAUM, Martha C.; SEN, Amartya; REYES MAZZONI, Roberto. La calidad de vida. México: Fondo de Cultura Econômica, 1996.

OUTHWAITE, William; BOTTOMORE, Tom (ed.). Qualidade de vida. In: Dicionário do pensamento social do século XX. Rio de Janeiro: Zahar, 1996. p. 635-636.

PETERSEN, Sílvia Regina F. Levantamento da produção bibliográfica e de outros resultados de investigação sobre a história operária e trabalho urbano fora do eixo Rio-São Paulo. Campinas: Cadernos do Arquivo Edgard Leuenroth, vol. 14, n. 26, p. 255-345, 2009.

RODRIGUES, Jaime. Alimentação, vida material e privacidade: uma história social de trabalhadores em São Paulo nas décadas de 1920 a 1960. São Paulo: Alameda, 2011. 
SABÓIA, João. Salário mínimo: a experiência brasileira. Porto Alegre: L\&PM, 1985.

SAGAR, Ambuj D.; NAJAM, Adil. The human development índex: a critical review. Ecological Economics, vol. 25, issue 3, p. 249-264, June 1998.

SALVATORE, Ricardo D.; COATSWORTH, John H.; CHALLÚ, Amílcar E. (eds.). Living Standards in Latin American history: height, welfare, and development, 1750-2000. Cambridge, London: Harvard University Press, 2010.

SEN, Amartya. Poor, relatively speaking. Oxford Economic Papers, vol. 35, p. 153-169, July 1983. . The Standard of Living. New York: Cambridge University Press, 1987.

SEN, Amartya; ANAND, Sudhir. Human Development Index: methodology and measurement. New York : Human Development Report Office, Occasional Papers, p. 1-19, July 1994.

SILVA, Nauber G. O que é padrão de vida: definição de um objeto para a historiografia do trabalho. Revista Latino-Americana de História, vol. 1, n. 3, p. 642-657, mar. 2012.

. Vivendo como classe: as condições de habitação e alimentação do operariado porto-alegrense entre 1905 e 1932. Porto Alegre: PPGHIST-UFRGS, 2010. Dissertação de Mestrado.

SURIANO, Juan. Cuál es hoy la historia de los trabajadores en la Argentina? Revista Mundos do Trabalho, vol. 1, no 1, p. 27-50, jan./jun. 2009.

THOMPSON, Edward P. A formação da classe operária inglesa. 3 vols. Rio de Janeiro: Paz e Terra, 1987.

VASCONCELOS, Francisco de A.; BATISTA FILHO, Malaquias. História do campo da Alimentação e Nutrição em Saúde Coletiva no Brasil. Ciência \& Saúde Coletiva, vol. 16, n. 1, p. 81-90, jan. 2011.

VASCONCELOS, Francisco de A. O nutricionista no Brasil: uma análise histórica. Campinas: Revista de Nutrição, vol. 15, nº 2, p. 127-138, mai/ago. 2002.

WOOD, Ellen M. Classe como processo e como relação. In: Democracia contra capitalismo. São Paulo: Boitempo, 2003. p. 73-98.

XXVI SIMPÓSIO NACIONAL DE HISTÓRIA. ANPUH: 50 ANOS. Anais eletrônicos. Disponível em: http://tinyurl.com/dx98dzp. Acesso em: 19 abr. 2012. 